\title{
REFLEXÕES SOBRE AS RELAÇõES ENTRE A HISTÓRIA DO SERVIÇO DOMÉSTICO E OS ESTUDOS DA PÓS-EMANCIPAÇÃO NO BRASIL
}

FLAVIA FERNANDES DE SOUZA

UNIVERSIDADE FEDERAL FLUMINENSE (UFF)

\begin{abstract}
RESUMO: Este texto apresenta algumas reflexões acerca da história do serviço doméstico em suas relações com a história da escravidão e da pósemancipação no Brasil, visando problematizar interpretações que costumam associar a história do trabalho doméstico remunerado a uma "herança escravista". Para isso, o texto apresenta duas partes. A primeira busca analisar alguns estudos clássicos das relações raciais, bem como algumas pesquisas históricas recentes voltadas para a pós-emancipação no Brasil, tendo em vista a presença do tema do serviço doméstico e a forma como ele foi analisado. No segundo momento, o texto volta-se para algumas questões importantes de ser consideradas no estudo da história do serviço doméstico para além da história da escravidão.
\end{abstract}

PALAVRAS-CHAVE: Serviço doméstico; História e Historiografia; Escravidão e Pós-emancipação.

ABSTRACT: This paper presents some thoughts on the history of domestic service in its relation with the history of slavery and post-emancipation in Brazil to discuss interpretations that usually associate the history of paid domestic work with a "lave heritage". For this, the text has two parts. The first seeks to analyze some classic study of race relations and some recent historical research focused on post-emancipation in Brazil, emphasizing of the presence of domestic service and the way it was analyzed. In the second part, the text turns to some important issues to be considered in the study of the history of domestic service in addition to the history of slavery.

KEYWORDS: Domestic service; History and Historiography; Slavery and postemancipation. 
O historiador, contudo, deve desconfiar de qualquer modelo que vê na continuidade, mais do que na mudança, a essência da experiência histórica ${ }^{1}$.

\section{Uma herança da escravidão?}

Durante a última década do século XIX e as primeiras do século $\mathrm{XX}$, em alguns dos mais conhecidos periódicos que circulavam na então Capital Federal e, também, em outras cidades brasileiras, o tema "serviço doméstico" ${ }^{2}$ foi um dos assuntos correntes. Naquela época, era comum a publicação de notícias e artigos em jornais e revistas sobre a chamada questão da famulagem ou a "crise dos criados" ${ }^{\prime \prime}$. De maneira geral, a discussão pública sobre esse assunto se dava em torno da problemática da regulamentação. Essa era defendida por vários setores patronais, dirigentes e intelectuais como uma necessidade urgente, que se impusera no contexto da abolição da escravidão e da imediata pós-emancipação no Brasil. Muitos daqueles que advogavam a existência de mecanismos reguladores no setor do trabalho doméstico acreditavam que a prestação de serviços realizada pelos criados domésticos encontrava-se "desorganizada" e "desmoralizada". Entre os problemas apontados por contemporâneos, no que se referia ao serviço doméstico na cidade do Rio de Janeiro, estavam: a suposta escassez de bons criados domésticos, que possuíssem qualidades profissionais e morais; a alta rotatividade de trabalhadores nos domicílios, que não permaneciam por muito tempo nos empregos; o alto número de criminosos que atuavam como servidores domésticos com o fim de roubarem as casas ou darem prejuízos às famílias cariocas; e o funcionamento de agências de locação de serviços que operavam de modo irregular, muitas das quais orientadas por estratégias desonestas de negociantes que visavam tirar vantagens de patrões e de empregados. Nesse contexto, então, emergiu o debate sobre a importância da criação de normas e de mecanismos de fiscalização públicos dos trabalhadores que desempenhavam

\footnotetext{
${ }^{1}$ FONER, Eric. Nada além da liberdade: a emancipação e seu legado. São Paulo: Paz e Terra, 1988, p. 69-70.

${ }^{2}$ Serviço doméstico era um termo genérico usado para fazer referência ao setor ocupacional constituído pelos criados domésticos ou criados de servir, como se denominava no período mencionado. Como indicam vários documentos da época, tal esfera do mundo do trabalho poderia incluir não só os empregados nos domićlios, mas, também, aqueles que desempenhavam funções em alguns estabelecimentos do comércio e da prestação de serviços da cidade. Entre as especialidades de domésticos estavam cozinheiros e ajudantes; copeiros; lavadeiras e engomadeiras; jardineiros e hortelãos; criados de quarto, camareiras e moços de hotel, cafés, casas de pasto ou hospedarias; mucamas e pajens; amas de leite e amas-secas; cocheiros particulares e seus auxiliares.

${ }^{3}$ Essas expressões, algumas vezes encontradas em matérias e notícias sobre o serviço doméstico, publicadas em periódicos no Rio de Janeiro no entre séculos XIX-XX, são também títulos ou questões tratadas em crônicas escritas por Gil, João do Rio e Lima Barreto, nas folhas Cidade do Rio (10 set. 1893), A Notícia (12 dez. 1909) e Correio da Noite (15 jan. 1915), respectivamente.
} 
as atividades domésticas. As iniciativas públicas feitas nesse sentido foram formuladas por representantes dos poderes municipais, autoridades policiais, e, até mesmo, negociantes atuantes no setor, visando ao controle do serviço doméstico, bem como o estabelecimento de regras para os contratos de trabalho entre amos e criados. E eram os jornais diários os espaços impressos privilegiados em que esse debate se manifestava de forma mais evidente.

Guardadas as especificidades de contextos históricos tão diversos e sem a intenção do cometimento de anacronismos, é possível dizer que cento e poucos anos depois, neste início de século XXI, o chamado trabalho doméstico remunerado, por vezes ainda chamado de serviço doméstico, aparece novamente como um tema atual na mídia brasileira. Na imprensa, de modo geral, nos últimos anos, esse é assunto que vez por outra vem à discussão. São várias as reportagens ou notícias divulgadas em impressos e eletrônicos tratando, por exemplo, do suposto fim do trabalho doméstico ${ }^{4}$ ou salientando a duradoura e frágil condição, em termos legais e sociais, em que permaneceu 0 enorme contingente de trabalhadores domésticos no Brasil ${ }^{5}$. Este, em 2009, era composto de 7,2 milhões de pessoas, das quais 93\% eram mulheres e, destas, $61 \%$ foram classificadas como negras ${ }^{6}$. $E$, à primeira vista, o que se coloca no debate sobre o trabalho doméstico remunerado, mais uma vez, é a questão da regulamentação. Isso especialmente desde o debate iniciado em 2010, com a tramitação de Proposta de Emenda Constitucional (PEC), e a sua promulgação, em 2013, que estendeu direitos trabalhistas elementares aos empregados domésticos - até então em condição peculiar no quadro dos trabalhadores assalariados do Brasil. Sendo assim, o tema do trabalho/serviço doméstico ${ }^{7}$ ganhou ainda maior repercussão pública, seja na imprensa, em agências

\footnotetext{
${ }^{4}$ CARRANCA, Adriana. Brasileiro foge do trabalho doméstico. O Estado de São Paulo, São Paulo, 30 mar. 2013. Disponível em: <http://economia.estadao.com.br/noticias/geral,brasileiro-fogedo-trabalho-domestico,148975e>. Acessado em: 1/9/2014; CORONATO, Marcos, MOURA, Marcelo et. al. Por que a empregada sumiu. Época, São Paulo, 20 jan. 2012. Disponível em: <http://revistaepoca.globo.com/vida/noticia/2012/01/por-que-empregada-sumiu.html>.

Acessado em: 01/09/2014; SILVA, Adriano. O começo do fim do emprego doméstico no Brasil. Exame, São Paulo, 15 Jun. 2011. Disponível em: http://exame.abril.com.br/rede-deblogs/manual-do-executivo-ingenuo/2011/06/15/o-comeco-do-fim-do-emprego-domestico-nobrasil/. Acessado em: 1/9/2014.

${ }^{5}$ SARRES, Caroline. Menos de $40 \%$ dos empregados domésticos no Brasil tem registro. Carta Capital, 19 jul. 2012. Disponível em: <http://www.cartacapital.com.br/sociedade/menos-de-40dos-empregados-domesticos-no-brasil-tem-registro/>. Acessado em 1/9/2014; BRASIL tem o maior número de domésticas do mundo, diz OIT. G1, 9 jan. 2013. Disponível em: <http://g1.globo.com/concursos-e-emprego/noticia/2013/01/brasil-tem-o-maior-numero-dedomesticas-do-mundo-diz-oit.html>. Acessado em: 01/09/2014.

${ }^{6}$ INSTITUTO DE PESQUISA ECONÔMICA APLICADA (IPEA). Situação atual das trabalhadoras domésticas no país. Comunicado n. 90, maio 2011, p. 4.

7 Ainda que existam distinções entre o "trabalho doméstico" (realizado por um ou mais membros de um grupo familiar para a sua subsistência) e o "serviço doméstico" (prestado por trabalhadores designados para a realização do trabalho de manutenção e de cuidado em domicílio de um núcleo familiar ao qual ele não pertence), neste texto não se dará preferência a nenhuma das designações, tendo em vista o seu uso corrente e indiscriminado em discussões e estudos brasileiros sobre $o$ assunto.
} 
oficiais ou organizações relacionadas a setores patronais e de empregados, em função da nova lei, que entrou definitivamente em vigor no País em 2015. Mas, como era de se esperar, diferentemente da virada do século XIX para o século $\mathrm{XX}$, agora, na contemporaneidade, são outros os termos do debate sobre a prestação de serviços domésticos e sua regulamentação. Como resultado de longo período de transformações sociais e de movimentos de lutas pela extensão de direitos, o que está em pauta no presente momento de discussão é o fim da exclusão e da distinção em que se encontravam os empregados domésticos em relação aos demais trabalhadores brasileiros.

No entanto, ao se considerar elementos de tal dinâmica de permanências e de mudanças históricas, é possível dizer que, apesar da perspectiva de a regulamentação ser completamente diferente nos dias correntes, talvez uma questão seja comum entre 0 passado e o presente no que se refere à prolongada "atualidade" do tema trabalho doméstico no Brasil: tanto no início do século XX quanto no início do século XXI, a escravidão, como parte da história ou de memórias construídas sobre o passado, é, com frequência, evocada nas discussões sobre o assunto. Isso porque, no final do século XIX e nas primeiras décadas do século $X X$, era comum se associar os supostos problemas do setor ocupacional composto pelos trabalhadores domésticos ao fim do sistema escravista. Em vários discursos da época, o fato de a escravidão doméstica ter sido uma das principais modalidades de exploração do trabalho e de dominação social era quase sempre lembrado como um ponto de referência para se pensar no suposto estado problemático da prestação de serviços domésticos pelos trabalhadores livres no contexto da abolição e da imediata pós-emancipação ${ }^{8}$. De outra parte, atualmente, os problemas do emprego doméstico são também geralmente associados ao passado escravista e a própria modalidade do trabalho doméstico remunerado é constantemente relacionada ao trabalho escravo. Nos discursos veiculados em diferentes setores da mídia brasileira é possível encontrar inúmeras referências que relacionam o serviço doméstico - e seus problemas atuais - como decorrentes da ou como diretamente relacionados à existência da escravidão no passado brasileiro. E os argumentos que recuperam esse tipo de relação de causalidade ou de "raízes históricas" são utilizados nas mais diferentes análises do tema, seja nas versões oficiais (oriundas de agências de notícia ou de pesquisa) ${ }^{9}$ ou em reportagens e matérias diversas de conjuntura - entre as quais se encontram, até mesmo, as mais críticas. ${ }^{10}$ Afinal, todas elas ressaltam elementos do que seria o "nefasto legado" ou a "herança perversa" da escravidão na história brasileira.

\footnotetext{
${ }^{8}$ SOUZA, Flavia Fernandes de. Para casa de família e mais serviços: o trabalho doméstico na cidade do Rio de Janeiro no final do século XIX. Dissertação (Mestrado em História) - Faculdade de Formação de Professores, Universidade do Estado do Rio de Janeiro. São Gonçalo, 2010, cap. 3.

${ }^{9}$ Entre os vários exemplos existentes pode-se aqui citar: IPEA. Situação atual das trabalhadoras domésticas no país - Comunicado no 90, maio 2011, p. 5; TRABALHO doméstico no Brasil tem ranço na escravidão. Agência Senado, Brasília, 27 abr. 2011. Disponível em: <http://www12.senado.gov.br/noticias/materias/2011/04/27/trabalho-domestico-no-brasil-temo-ranco-da-escravidao >. Acessado em: 10/12/2014.

${ }^{10}$ Encontram-se exemplos em: LOPES, Roberta. Descendente da escravidão, trabalho doméstico ainda tem maioria negra. Rede Brasil Atual, 27 abr. 2011. Disponível em:
} 
Sendo assim, pode-se supor que, se no início do século XX parecia ser mais óbvia a explicação dada pela escravidão - uma vez que havia, inclusive, uma maior proximidade histórico-temporal -, neste início de século XXI tais aproximações entre trabalho doméstico e escravidão se dão de maneiras menos explícitas. Comumente a associação feita entre o trabalho doméstico e 0 trabalho escravo se dá por dois fatores: pela cor dos trabalhadores - tendo em vista o grande percentual de trabalhadoras domésticas negras - e pela precariedade, até bem pouco tempo, em termos de direitos trabalhistas e a alta informalidade no setor. Ambas as questões são geralmente tratadas em suas relações com o fato de a maioria dos trabalhadores domésticos serem mulheres, atuando em espaços privados - portanto, invisíveis à fiscalização do poder público e com enormes dificuldades associativas -, e sendo alvo de exploração, desvalorização e discriminação. Assim, nas análises atuais divulgadas na mídia sobre a questão dos empregados domésticos são fartas as referências explicativas que ligam o passado escravista brasileiro ao presente de alto percentual de mulheres negras que atuam como domésticas - em geral, pobres, migrantes e pouco escolarizadas e/ou qualificadas. Na realidade, essa é uma tópica comum nas discussões do tema, mas que tendencialmente se apresenta como autoexplicativa. De outra parte, se coloca a questão das condições de trabalho, que ocorrem em um âmbito privado, por longo tempo sem regras claras e de difícil supervisão pública. Nesse caso, por ser o trabalho doméstico remunerado uma atividade profissional que se caracteriza pela prestação de serviços pessoais e por relações de trabalho que podem ser caracterizadas por alto nível de intimidade e/ou de afetividade, mais uma vez, as aproximações com o passado escravista brasileiro se colocam como óbvias, especialmente no que se refere à exploração do trabalho e ao desrespeito a direitos humanos.

Considerando essas questões, este texto busca refletir sobre a ideia de "herança" que permeia as discussões passadas e presentes sobre o trabalho doméstico remunerado ou o serviço doméstico e que o associam de forma determinista à escravidão (geralmente apresentada como uma ideia abstrata e

<http://www.redebrasilatual.com.br/trabalho/2011/04/descendente-da-escravidao-trabalhodomestico-ainda-tem-maioria-de-negras>. Acessado em: 10/12/2014; MARIZ, Renata. As domésticas que abolição esqueceu. Correio Braziliense, Brasília, 11 nov. 2012. Disponível em: <http://www.cartapotiguar.com.br/2012/11/11/empregada-domestica-uma-heranca-daescravidao/>. Acessado em: 10/12/2014; VALENTIN, Gabriela; Mendonça, Carolina. Empregada doméstica: trabalho ou escravidão? $A$ verdade, 12 jun. 2012. Disponível em: < http://averdade.org.br/2012/06/empregada-domestica-trabalho-ou-escravidao/>. Acessado em: 10/12/2014; As empregadas e a escravidão. Pragmatismo Político. 12 nov. 2014. Disponível em: <http://www.pragmatismopolitico.com.br/2014/11/empregadas-domesticas-eescravidao.html>. Acessado em: 05/01/2015; ANTUNES, Ricardo. A revolta da sala de jantar. $O$ Estado de São Paulo, São Paulo, 30 mar. 2013. Seção Aliás. Disponível em: $<$ http://alias.estadao.com.br/noticias/geral,a-revolta-da-sala-de-jantar,1015042>. Acessado em: 10/12/2014; BRAGA, Ruy. Desassossego na cozinha. O Estado de São Paulo, São Paulo, 19 jan. 2013. Seção Aliás. Disponível em: <http://alias.estadao.com.br/noticias/geral,desassossego-na-cozinha,986356>. Acessado em: $10 / 12 / 2014$. 
não necessariamente relacionada à história da escravidão). Isso tendo em vista certas interpretações já consolidadas no "senso comum histórico" e reproduzidas em análises e narrativas do tema - tal como aparece expressa em textos jornalísticos, que repetem "a torto e a direito" expressões como resquício, ranço, marca, legado ao tratar do assunto. Não obstante, pensando sob a lógica da História, ainda que seja fato incontestável a existência de relações e consequências sociais, políticas, econômicas e culturais de séculos de escravidão na formação social brasileira - o que pode ser afirmado para inúmeros outros fenômenos históricos -, caberia, nesse caso, uma reflexão sobre a seguinte questão: seriam os problemas contemporâneos do trabalho doméstico remunerado unicamente justificáveis pelo passado escravista brasileiro? A hipótese de fundo a partir da qual essas reflexões foram construídas é a de que embora não se possa analisar a história do trabalho/serviço doméstico no Brasil de forma dissociada da história da escravidão, em especial em sua modalidade urbana e doméstica, a compreensão histórica do estado atual do trabalho doméstico remunerado não pode ser completamente compreendida sem se levar e conta processos históricos desenrolados no que se convencionou chamar de pós-emancipação.

Desse modo, com a intenção de trazer elementos para se pensar nesse pressuposto, o movimento que se fará no presente texto se dará em dois sentidos. $O$ primeiro momento procura referências sobre as relações entre 0 serviço doméstico e a suposta "herança escravista" nas produções historiográficas sobre o período pós-abolição. Para isso se busca, inicialmente, alguns estudos clássicos sobre o assunto, realizados inicialmente por estudiosos das relações raciais no Brasil, cuja influência nas análises do tema se percebe até os dias correntes; e, depois, se recuperará alguns exemplos de estudos históricos atuais voltados para a pós-emancipação no Brasil. No segundo momento do texto, a proposta é realizar uma pequena reflexão sobre algumas questões que talvez tragam elementos para uma problematização da relação comumente feita, no senso comum e também em estudos sociais e históricos, entre trabalho doméstico remunerado e escravidão no Brasil.

\section{O tema do serviço doméstico em estudos das relações raciais e da pós-emancipação}

Ainda que o interesse e a construção da pós-emancipação ou do pósabolição como um problema histórico seja relativamente recente entre os historiadores brasileiros, preocupações com o destino da sociedade brasileira após o fim da escravidão foram de longa data alvo de pesquisas ${ }^{11}$. Isso ocorreu incialmente a partir da constituição do campo dos estudos das relações raciais, que, se por um lado, se desenvolveu, em grande parte, em consequência da produção de Gilberto Freyre, em seus estudos sobre os matizes étnicos

\footnotetext{
${ }^{11}$ RIOS, Ana Lugão; MATTOS, Hebe. Memórias do cativeiro: família, trabalho e cidadania no pós-abolição. Rio de Janeiro: Civilização Brasileira, 2005, p. 17.
} 
fundadores da nossa formação social e cultural e o papel da miscigenação na constituição das relações sociais e raciais brasileiras; por outro lado, o campo dos estudos das relações raciais se renovaram com uma série de pesquisas, realizadas especialmente por sociólogos, nos anos 1950, e que problematizaram os entendimentos estabelecidos acerca das interações entre negros e brancos no Brasil. Nesse caso, por intermédio da proposta da Unesco para o patrocínio de investigações em diferentes regiões do País, várias pesquisas foram realizadas ao longo da década de 1950 com o objetivo de identificar fatores econômicos, sociais, políticos e culturais favoráveis ou não à existência de desigualdades raciais na sociedade brasileira. E, de maneira geral, todos os estudos desenvolvidos nesse âmbito tiveram como uma das preocupações centrais a reflexão sobre a inserção dos negros na modernidade, tendo em vista o passado escravista na formação social do País.

Embora as investigações feitas pela produção oriunda dos estudos sobre a questão racial brasileira - a qual teve grande repercussão posterior compreendessem um conjunto amplo e variado de temas, o foco sobre o qual recaíram as pesquisas empreendidas no referido contexto foi o dos contatos inter-raciais no Brasil. Esses normalmente foram traduzidos por fenômenos como preconceito de cor, por sua vez abordados em sua conexão com assuntos como: o padrão de desenvolvimento econômico e social; a integração, a mobilidade e as estratificações sociais; a urbanização e a industrialização; as relações e contradições na transição do arcaico para o moderno; entre outros temas $^{12}$. Contudo, analisando algumas pesquisas desenvolvidas em meados do século XX por estudiosos das relações raciais, incluindo a obra pioneira de Gilberto Freyre, pode-se perceber que a temática do trabalho e dos trabalhadores domésticos muitas vezes emergiu naquela produção. Isso se deu de modo particular em estudos que se direcionaram para análises que envolviam questões relativas à constituição do mercado de trabalho livre em algumas cidades brasileiras, como foi o caso dos estudos de Florestan Fernandes, Roger Bastide e L. A. Costa Pinto para as cidades de São Paulo e Rio de Janeiro, respectivamente ${ }^{13}$.

Em primeiro lugar, é importante destacar que em Casa grande \& senzala, observações sobre o serviço doméstico apareceram com frequência em análises e reflexões feitas em torno da escravidão brasileira e das relações existentes entre os mundos opostos e complementares de senhores e de escravos. $\mathrm{Na}$ realidade, ao se voltar para os aspectos do cotidiano privado e familiar em tempos coloniais, Freyre enfatizou a escravidão doméstica como um elemento fundamental na formação histórica, social e cultural brasileira. Em várias partes do livro, principalmente nos capítulos dedicados ao "escravo negro", o autor fez

\footnotetext{
${ }^{12}$ MAIO, Marcos Chor. Projeto Unesco: ciências sociais e "credo racial brasileiro". Revista USP, São Paulo, n. 46, p. 115-128, junho/agosto 2000, p. 121.

${ }^{13}$ BASTIDE, Roger; FERNANDES, Florestan. Brancos e negros em São Paulo: ensaio sociológico sobre aspectos da formação, manifestações atuais e efeitos do preconceito de cor na sociedade paulista. 4a ed. São Paulo: Global, 2008; PINTO, L. A. Costa. O negro no Rio de Janeiro: relações de raça em sociedade em mudança. $2^{a}$ ed. Rio de Janeiro: UFRJ, 1998.
} 
inúmeras referências aos cativos alocados no trabalho doméstico das casas grandes. Mais do que isso, ao argumentar sobre aspectos da benignidade da escravidão brasileira, Freyre enfatizou o papel da escravidão doméstica, ao pôr em relevo "a doçura nas relações de senhores com escravos domésticos, talvez maior no Brasil do que em qualquer outra parte da América" ${ }^{14}$. Segundo Freyre, o serviço doméstico poderia ser visto também como um mecanismo de ascensão para os escravos, que, devido a qualidades físicas e morais, subiam da senzala para "serviço mais íntimo e delicado dos senhores"15. E na interpretação do autor, na hierarquia da escravatura, "a parte aristocrática eram os escravos do serviço doméstico", havendo, mesmo entre esses, "distinções marcadas pelo status ${ }^{\prime 16}$.

No entanto, tendo como foco de maior atenção os estudos da década de 1950, nota-se que no ensaio sociológico de Florestan Fernandes e de Roger Bastide, publicado em 1955, encontram-se, em alguns capítulos, vários apontamentos que fazem referência ao trabalho doméstico, particularmente em suas reflexões sobre a passagem do escravo para cidadão. Interessado no processo de integração dos ex-escravos e seus descendentes no mundo do trabalho urbano, o autor afirma que "a lenta reabsorção do elemento negro no sistema de trabalho" se deu "a partir de ocupações mais humildes e mal remuneradas", entre as quais estaria o emprego doméstico ${ }^{17}$. Segundo Fernandes, "somente as atividades mais simples, que exigiam aptidões elementares, ou as atividades confinadas aos serviços domésticos, todas elas em conjunto pessimamente retribuídas, é que podiam ser disputadas aos brancos pelos egressos do regime servil" ${ }^{18}$. Nas cidades, como em São Paulo, estudada por Fernandes, parte predominante dos ex-escravos ocuparam-se com a prestação de serviços domésticos no imediato pós-abolição. $E$ entre esses estariam, sobretudo, mulheres, para quem Florestan acreditava ter sido "mais fácil" a transição para o trabalho livre, uma vez que "no mundo escravo o aviltamento dos serviços domésticos não chegara a ser tão acentuado quanto o de outras atividades manuais ou braçais, realizadas pelos cativos ${ }^{\prime 19}$. $\mathrm{Na}$ interpretação de Fernandes, tal situação, dada pela permanência das mulheres negras nos serviços domésticos, talvez tenha até contribuído para que os homens, na ausência de alternativas, pudessem "viver de expediente" ou de pequenos biscates, pois poderiam contar com a cooperação das companheiras empregadas na prestação de serviços domésticos. Segundo o autor, as mulheres engajadas em tal atividade laboral puderam, até mesmo, ajudar seus companheiros, ao disponibilizar "alojamento (em quartos de aluguel, dos

\footnotetext{
${ }^{14}$ FREYRE, Gilberto. Casa grande \& senzala: Introdução à história da sociedade patriarcal no Brasil - 1. 20a ed. São Paulo: Círculo do Livro, 1980, p. 371.

${ }^{15}$ Ibid.

${ }^{16}$ FREYRE. Op. cit., p. 489.

${ }^{17}$ BASTIDE, Roger; FERNANDES, Florestan. Brancos e negros em São Paulo: ensaio sociológico sobre aspectos da formação, manifestações atuais e efeitos do preconceito de cor na sociedade paulista. 4a ed. São Paulo: Global, 2008, p. 71.

${ }^{18}$ Ibid., p. 72.

${ }^{19}$ Ibid., p. 74.
} 
porões ou dos cortiços); alimentação (geralmente 'trazida do emprego'); roupas velhas (obtidas dos patrões); e algum dinheiro (extraído do próprio ganho)"20.

De acordo com a análise de Florestan Fernandes, portanto, o serviço doméstico teria cumprido um papel importante para as comunidades negras após o fim da escravidão, já que empregou parte substancial das ex-escravas. Todavia, na sua interpretação essa seria parte de "uma herança negativa deixada pela escravidão", visto que o emprego doméstico se constituiu como uma das atividades laborais degradadas pelo sistema escravista e que ficaram mais restritas aos negros após a Abolição. Na verdade, tal interpretação de Fernandes para o processo de transição do trabalho escravo para o trabalho livre fazia parte de sua tese e de toda a sua argumentação a respeito das relações entre brancos e negros em São Paulo. Para o autor, a questão racial teve como determinante primário o escravismo. Em sua visão, a escravidão, como sistema econômico e instituição social, fora extremamente prejudicial à formação social brasileira, pois além de afetar aqueles que viveram a experiência do cativeiro, teria deixado para o futuro da sociedade uma herança de preconceitos, anomia e patologia sociais. Isso porque os negros, entendidos como descendentes dos escravos, não teriam conseguido se integrar, de fato, à dinâmica social, devido a problemas como a discriminação, o analfabetismo, a pobreza e a criminalidade legados pelo passado escravista. A escravidão é compreendida, então, por Florestan Fernandes, como elemento de "desagregação" social, que moldou o futuro dos negros, marginalizando-os e relegando-os a posições de subordinação.

Em uma perspectiva de análise semelhante à de Florestan Fernandes, Roger Bastide, o segundo autor do ensaio sociológico sobre brancos e negros em São Paulo, voltou-se para o estudo de evidências de manifestações e efeitos do preconceito de cor. Nesse trabalho, Bastide fez algumas importantes referências ao tema do trabalho doméstico ao discutir a questão dos mecanismos discriminatórios e/ou atitudes de preconceitos então existentes em meados do século XX em relação aos negros. Ao estudar diferentes grupos sociais, o autor identificou comportamentos e discursos que tendiam a associar, depreciativamente, os negros a certas atividades profissionais, consideradas socialmente como subalternas, tal como seria o caso do serviço doméstico. Segundo Bastide,

[...] a família tradicional, habituada ao contato íntimo com o negro na escravatura, aceito-o sempre como doméstico e tratao com bondade, contanto que lhe fique no seu lugar, enquanto a burguesia saída da imigração se recusa a pactuar com 0

\footnotetext{
${ }^{20}$ BASTIDE, Roger; FERNANDES, Florestan. Brancos e negros em São Paulo: ensaio sociológico sobre aspectos da formação, manifestações atuais e efeitos do preconceito de cor na sociedade paulista. 4a ed. São Paulo: Global, 2008, p. 75.
} 
negro, mesmo quando este último tem uma posição subordinada. Repele-o pura e simplesmente ${ }^{21}$.

Em observações como essas, o autor apontou para uma série de estereótipos de cor e preconceitos de classe que, muitas vezes combinados, vinculavam os negros, especialmente as mulheres, à profissão de empregado(a) doméstico(a). Assim, o autor mencionou casos em que as mulheres negras tendiam a ser sempre vistas como criadas de servir, independentemente de sua posição social ${ }^{22}$. De outra parte, Bastide também fez alusões ao trabalho doméstico ao discutir questões como barreiras raciais que dificultavam a ascensão social ou, simplesmente, a escolha de profissões dos negros em São Paulo ${ }^{23}$.

Com a proposta comum dos estudos das relações raciais, a obra de L. A. Costa Pinto para o Rio de Janeiro (1953) - mais um dos estudos produzidos em torno do projeto da Unesco nos anos 1950 -, apresentou igualmente um olhar atento para 0 trabalho doméstico remunerado. $O$ autor realizou uma pesquisa aprofundada em torno da ideia de "transição social" nas relações entre brancos e negros em uma sociedade impactada pela urbanização e a industrialização ${ }^{24}$. Com a preocupação de analisar a transformação dos escravos em proletários e seus desdobramentos e impactos nas interações raciais, Costa Pinto verificou a forte representação dos grupos sociais de cor (preta e parda) no setor ocupacional composto pelos empregados domésticos e justificando a relevância do tema para seu estudo, ponderou:

Observemos, por exemplo, o emprego doméstico, cuja significação para o nosso estudo resulta não apenas da importância estatística e do número elevado das que se dedicam a essa atividade, mas também pela importância que isso tem no condicionar, desde a infância, atitudes e estereótipos na criança brasileira a respeito da posição 'natural' da mulher de cor na sociedade ${ }^{25}$.

Em uma análise minuciosa dos dados encontrados sobre o tema, Costa Pinto ressaltou a existência de hierarquias de posições e de linhas de sexo, de cor e de classe no que se refere ao serviço doméstico. Além disso, o autor fez um exercício original de análise que buscou pensar o trabalho doméstico remunerado em suas relações com a estratificação social, a condição étnica e a situação espacial no Rio de Janeiro de meados do século XX. Nesse caso, Costa

\footnotetext{
${ }^{21}$ BASTIDE, Roger; FERNANDES, Florestan. Brancos e negros em São Paulo: ensaio sociológico sobre aspectos da formação, manifestações atuais e efeitos do preconceito de cor na sociedade paulista. $4^{a}$ ed. São Paulo: Global, 2008, p. 163.

${ }^{22}$ Ibid., p. 166.

${ }^{23}$ Ibid., p. $172-182$.

${ }^{24}$ Sobre o assunto ver: GOMES, Flávio dos Santos. Em torno da herança: do escravo-coisa ao negro-massa. Escravidão nos estudos das relações raciais no Brasil. In: MAIO, Marcos Chor; BÔAS, Glaucia Villas. Ideias de modernidade e sociologia no Brasil: ensaios sobre Luiz Aguiar Costa Pinto. Porto Alegre: UFRGS, 1999, p. 125-144.

${ }^{25}$ PINTO, L. A. Costa. $O$ negro no Rio de Janeiro: relações de raça em sociedade em mudança. $2^{a}$ ed. Rio de Janeiro: UFRJ, 1998, p. 117.
} 
Pinto identificou a distribuição dos empregados domésticos em diferentes circunscrições do então Distrito Federal, observando, por exemplo, a maior ou a menor concentração de empregados domésticos em determinadas áreas da cidade $^{26}$.

A partir de uma rápida análise da produção clássica e mais conhecida sobre as relações raciais no Brasil, sobretudo a dos anos 1950, como no caso dos trabalhos de Costa Pinto, de Roger Bastide e de Florestan Fernandes, é possível dizer que nas pesquisas inaugurais que tiveram a pós-emancipação como objeto de estudos - ainda que pensada em termos de questão racial ou de destino dos ex-escravos após a Abolição - o tema trabalho doméstico veio à tona como elemento importante de análise para alguns autores no que se referia aos seus temas de estudo. Assim como parte de toda a argumentação então elaborada para o entendimento das relações entre negros e brancos que vinculava tais relações à escravidão, como origem e determinante de uma série de processos históricos desenrolados posteriormente a seu término -, 0 serviço doméstico, como atividade ocupacional realizada por considerável número de trabalhadores negros, foi pensado no quadro do legado escravista às gerações descendentes dos escravos ou de um recente passado de escravidão, cujas marcas eram ainda bem visíveis. Ou seja, como atividade profissional degradada e subalterna e como um dos "lugares sociais de desvantagens" construídos pelo escravismo e que fora perpetuado ao ser ocupado por milhares de homens e de mulheres afrodescendentes mesmo após a Abolição.

No entanto, se em estudos clássicos das relações raciais o trabalho doméstico remunerado - por abrigar alto percentual de negros - apareceu como um elemento relevante de análise, em estudos subsequentes sobre a questão racial, o tema foi mencionado, mas sem ser objeto de maiores atenções. Esse foi o caso das pesquisas empreendidas nos 1970 e 1980 por Carlos Hasenbalg e George Andrews ${ }^{27}$. Ambos os autores se dedicaram igualmente ao estudo a questão racial no Brasil, porém em perspectiva diferente dos estudos anteriores. De maneira geral, Hasenbalg e Andrews colocaram-se em posição crítica à ideia de que as desigualdades raciais brasileiras são parte da herança deixada pela escravidão para a sociedade, tendo as práticas de preconceito cor e de discriminação racial suas origens na constituição da sociedade escravista ${ }^{28}$.

Carlos Hasenbalg, por exemplo, foi um dos primeiros a pensar os problemas relativos às relações raciais no Brasil com um problema do período pós-abolição. Segundo ele,

\footnotetext{
${ }^{26}$ Ibid., p. $134-136$.

${ }^{27}$ HASENBALG, Carlos Alfredo. Discriminação e desigualdades raciais no Brasil. Trad. de Patrik Burglin. Rio de Janeiro: Edições Graal, 1979; ANDREWS, George Reid. Negros e brancos em São Paulo (1888-1988). Trad. de Magda Lopes. Bauru, SP: EDUSC, 1988.

${ }^{28}$ Importante ressaltar que as críticas dos autores se estendem a produção anterior a dos anos 1950 e que influenciou a formulação de interpretações posteriores que defendiam a existência de uma democracia racial no Brasil.
} 
[...] um ponto central da análise consiste em desenfatizar o legado do escravismo como explicação das relações raciais contemporâneas e, ao invés disso, acentuar o racismo e a discriminação depois da abolição como uma das principais causas da subordinação social dos não brancos e seu recrutamento a posições sociais inferiores ${ }^{29}$.

De outra parte, seguindo uma via crítica semelhante, o estudo de George Andrews para a cidade de São Paulo contestou a tese defendida por Florestan Fernandes, problematizando a ênfase dada à escravidão para o entendimento das relações entre brancos e negros no século XX. Para Andrews, o risco de se considerar a escravidão como "determinante primário das relações raciais atuais" é o de perder de vista as "maneiras como as novas condições históricas alteraram e transformaram a herança da escravidão"30.

Não obstante, na produção representada por Hasenbalg e Andrews, tal mudança de enfoque não significou um maior interesse pelo estudo do trabalho doméstico para a compreensão da questão racial no Brasil. Na realidade, esse assunto foi algumas vezes mencionado como um dado que ajudaria a pensar nas problemáticas das relações raciais, sobretudo no que se refere à trajetória de vida e de trabalho dos ex-escravos e seus descendentes após o fim da escravidão. Ao analisarem a estrutura ocupacional brasileira, no final do século XIX e ao longo do século XX, ambos os autores apenas indicaram que os negros, particularmente as mulheres, permaneceram super-representados no setor da prestação de serviços domésticos.

O historiador George Andrews - assim como já havia indicado Florestan Fernandes - chegou a pontuar a centralidade das atividades domésticas remuneradas, exercidas pelas mulheres, para a sobrevivência das famílias negras no imediato pós-abolição: "as mulheres negras dessas décadas evidentemente merecem muito, se não a maior parte, do crédito por terem sustentado a comunidade negra durante uma época em que as oportunidades alternativas de emprego eram quase inexistentes". Já o sociólogo argentino Carlos Hasenbalg demonstrou, por exemplo, que, em 1950, "89\% das mulheres de cor empregadas fora das atividades primárias e industriais concentravam-se nos serviços pessoais, principalmente no emprego doméstico". E sem esmiuçar fatores que explicariam tais processos, ambos os autores apenas indicaram que esses fenômenos seriam reveladores de aspectos da dinâmica das relações raciais no período posterior à Abolição.

Considerando, então, algumas obras clássicas nos estudos das relações raciais no Brasil por suas preocupações com questões da pós-emancipação, tendo a intenção de buscar pistas sobre como o tema do trabalho doméstico remunerado foi abordado, pode-se fazer algumas observações. Em primeiro lugar, destaca-se o fato de que questões sobre o trabalho doméstico emergiram naquela produção como um elemento que, em maior ou menor grau, deveria ser considerado nas análises, uma vez que todas as pesquisas chamaram a

\footnotetext{
${ }^{29}$ HASENBALG. Op. cit., p. 21.

${ }^{30}$ ANDREWS, George Reid. Op. cit., p. 27.
} 
atenção para o alto percentual de trabalhadores negros, sobretudo mulheres, atuando como empregados(as) domésticos(as) em algumas das principais cidades brasileiras desde o final do século XIX e se estendendo por todo o século XX. Aliado a isso, em alguns estudos foram feitas referências à existência de atitudes desfavoráveis, de preconceito ou de discriminação, em relação aos trabalhadores domésticos - sendo a própria atividade profissional vista como subalterna e precária. Ou seja, o serviço doméstico foi entendido como um espaço tendencialmente ocupado por negros, que, por sua vez, constituíam um grupo social discriminado na sociedade brasileira.

Uma segunda observação é que em boa parte daquela produção sobre as relações raciais defendeu-se a ideia de que a escravidão estaria na origem das desigualdades raciais existentes no século XX. De certa forma, seria 0 passado escravista responsável por estigmatizar profissões, que se antes eram exercidas por escravos, na pós-emancipação passaram a ser espaço de atuação dos segmentos sociais "de cor". Nesse caso, mesmo com críticas posteriores, que procuraram enfatizar o peso do contexto histórico da pós-emancipação para a existência das desigualdades raciais na sociedade brasileira do século $\mathrm{XX}$, a forte presença de trabalhadores negros empregados como domésticos foi mais aprofundada no sentido de compreendê-la como parte das consequências históricas geradas pela escravidão. Assim, questões relativas ao trabalho doméstico permaneceram sendo buscadas em sua relação com a permanência da atuação de ex-escravos e seus descendentes na organização do mundo do trabalho após a Abolição. Finalmente, em terceiro lugar, é possível dizer que naqueles estudos, tendo em vista o seu foco na análise das relações raciais, a discussão sobre o serviço doméstico apareceu unicamente atrelada à participação feminina negra no mercado de trabalho. E a partir de então, e com grande fundamento em dados concretos da realidade, "trabalho doméstico" e "empregadas negras" passaram a ser chaves temáticas comuns nas discussões sobre relações raciais.

É importante salientar que todas essas questões - se não desenvolvidas, ao menos tocadas pelos estudiosos das relações raciais entre as décadas de 1950 e 1980 - ainda são consideradas relevantes no que se refere ao tema do serviço doméstico na atualidade. Como já se comentou inicialmente, grande parte das discussões atuais sobre o trabalho doméstico remunerado no Brasil faz referência a algum daqueles pontos. Em alguns momentos, parece mesmo que argumentos utilizados para a existência de desigualdades raciais são repetidos em análises sobre o trabalho doméstico. Isso porque, de uma perspectiva geral, são frequentes as referências ao serviço doméstico como parte das consequências geradas pela escravidão existente no passado brasileiro, sobretudo no que se refere às relações raciais. Nesse caso, é interessante notar que o próprio tema, serviço doméstico, perde a sua historicidade, pois raramente se considera a sua história ou dos seus trabalhadores para além da sua relação histórica com o escravismo no Brasil. Desse modo, seja ou não pela permanência da validade de explicações formuladas por aqueles estudiosos das relações raciais, o trabalho doméstico 
remunerado tende a ser visto unicamente como decorrente da escravidão e como espaço a partir do qual podem ser buscadas evidências de preconceitos e discriminações raciais. Mas, se isso acontece em relação aos estudos raciais, seria talvez interessante pensar em como o trabalho doméstico aparece em parte da historiografia brasileira recente que vem se dedicando - direta ou indiretamente - à pós-emancipação, e de que forma as suas análises poderiam influenciar algumas visões contemporâneas sobre o trabalho doméstico remunerado no Brasil.

Ainda que não haja no momento uma clara definição de uma área de estudos na historiografia brasileira que possa ser definida como propriamente da pós-emancipação, tem ocorrido nas últimas décadas um esforço de alguns historiadores para tratar com mais especificidade dos processos históricos desenrolados no Brasil como parte dos desafios de (re)construção de uma sociedade pós-escravista. Isso porque em sociedades outras que conheceram a escravidão - em suas múltiplas temporalidades - foi comum a ocorrência de situações históricas específicas após o fim do sistema escravista e que podem ser denominadas como próprias da pós-emancipação. Esse seria, por exemplo, o caso de conflitos envolvendo diferentes formas de exploração do trabalho; da construção de identidades e de classificações sociais baseadas em pressupostos racializados; ou da extensão e/ou da restrição de direitos de cidadania para os egressos do cativeiro e seus descendentes ${ }^{31}$. Sendo assim, diferentes pesquisas vêm sendo desenvolvidas por historiadores brasileiros cuja proposta investigativa procura, de alguma maneira, trazer luz para situações sociais que se impuseram durante e depois da abolição da escravidão no Brasil. E isso mesmo em contextos ainda escravistas, como em de parte do século XIX, mas que envolveram experiências complexas e relacionadas à pós-emancipação, como a conquista de alforrias e de formas de integração social dos exescravos $^{32}$.

Sem perder o foco do tema do serviço doméstico e direcionando a atenção para essa produção historiográfica interessada, de várias formas, no destino da sociedade brasileira para "além da escravidão", e sem a pretensão de apresentar um panorama detalhado do tema, destacam-se alguns estudos que tocaram em problemáticas relativas à história do trabalho e dos trabalhadores domésticos no Brasil. Tais pesquisas não foram, em sua maioria, definidas pelos seus autores como estudos da pós-emancipação, todavia trouxeram reflexões importantes nesse sentido. Afinal, um interesse comum entre os historiadores a serem mencionados foi o de pensar um pouco na trajetória de libertos e seus

${ }^{31}$ COOPER, Frederick; HOLT, Thomas; SCOTT, Rebecca J. Além da escravidão: investigações sobre raça, trabalho e cidadania em sociedades pós-emancipação. Trad. Maria Beatriz de Medina. Rio de Janeiro: Civilização Brasileira, 2005, p. 16.

32 Apenas para citar alguns trabalhos dessa natureza, pode-se mencionar: RIOS, Ana Lugão; MATTOS, Hebe. Memórias do cativeiro: família, trabalho e cidadania no pós-abolição. Rio de Janeiro: Civilização Brasileira, 2005; CUNHA, Olívia Maria dos Santos Gomes; GOMES, Flávio dos Santos. Quase cidadão: histórias e antropologias da pós-emancipação no Brasil. Rio de Janeiro: FGV, 2007; ALBUQUERQUE, Wlamyra R. de. O jogo da dissimulação: abolição e cidadania negra no Brasil. São Paulo: Cia das Letras, 2009; DOMINGUES, Petrônio; GOMES, Flávio dos Santos. Da nitidez e invisibilidade: legados do pós-emancipação no Brasil. Belo Horizonte, MG: Fino Traço, 2013. 
descendentes no mundo do trabalho livre. Além disso, embora os objetos de estudos de cada autor tenham sido diversos, todos tiveram que enfrentar 0 tema do trabalho doméstico, tal como ocorreu, de certa forma, com alguns estudos realizadas no campo das relações raciais.

O primeiro trabalho que pode ser aqui mencionado é o da historiadora e antropóloga Caetana Damasceno por envolver um esforço de resgate e de compreensão dos significados de categorias "étnico-raciais" em conjunturas de pós-emancipação ${ }^{33}$. Isso porque a autora levantou, entre outras, a relevante discussão acerca do surgimento da noção de "boa aparência" como um dos fatores a influenciar o percurso ocupacional de mulheres trabalhadoras, em especial de empregadas domésticas, no mundo do trabalho urbano carioca entre os anos 1930 e 1950. Ao enfrentar a análise de anúncios de oferta de emprego, Damasceno deparou-se com grande quantidade de anúncios sobre a prestação de serviços domésticos e, por meio da leitura de seus enunciados, procurou identificar as "sutis percepções quanto ao perfil dos candidatos a serem preferidos ou preteridos para ocupar determinados postos de trabalho". ${ }^{34}$ Como resultado desse esforço analítico Damasceno recuperou, para o período estudado, aspectos da dinâmica de preferências por empregadas domésticas "brancas", em detrimento daquelas "de cor" (pretas e pardas), ocorridas em função do "truque" da "boa aparência"35.

Outra importante referência que pode ser aqui referenciada é a pesquisa empreendida pelo historiador Walter Fraga Filho acerca de alguns dos itinerários seguidos por libertos após a abolição da escravidão na Bahia ${ }^{36}$. Com o interesse de esmiuçar as escolhas migratórias de ex-escravos do Recôncavo para as cidades, autor conseguiu recuperar algumas das formas mais comuns de inserção dos escravos no mundo do trabalho urbano, sendo atestado que o setor do "serviço doméstico" "era o que mais absorvia trabalho feminino saído dos engenhos" - embora não fosse essa, de acordo com o autor, uma ocupação exclusiva de mulheres ${ }^{37}$. 0 aprofundamento da investigação levou Fraga Filho a se debruçar sobre a documentação relativa às iniciativas dos representantes do poder municipal da cidade de Salvador, no final dos anos 1880, para a execução de uma postura municipal que regulamentasse o serviço doméstico. A análise dessas fontes - em particular dos livros de matrículas do serviço doméstico revelaram algumas características do setor ocupacional constituído pelos criados e criadas de servir na capital baiana. Entre estas estaria a predominância de trabalhadores de cor preta ou parda no setor, provavelmente egressos do cativeiro e um considerável número de trabalhadores domésticos migrantes, oriundos de áreas açucareiras do recôncavo baiano ${ }^{38}$.

\footnotetext{
33 DAMASCENO, Caetana Maria. Segredos da boa aparência: da "cor" à "boa aparência" no mundo do trabalho carioca, 1930-1950. Seropédica: UFRRJ, 2010.

${ }^{34}$ Ibid., p. 114.

${ }^{35}$ Ibid., p. 133.

${ }^{36}$ FRAGA FILHO, Walter. Encruzilhadas da liberdade: histórias de escravos e libertos na Bahia (1870-1910). Campinas, SP: Unicamp, 2006.

${ }^{37}$ Ibid., p. 325.

${ }^{38}$ Ibid., p. 334-336.
} 
A pesquisa do historiador Henrique Espada Lima pode ser, por fim, mencionada como outro relevante exemplo visto que trouxe uma análise que envolve a trajetória de escravos alforriados, num contexto ainda escravista ${ }^{39}$. Interessado no estudo dos contratos de locação de serviços, e nos ajustes estabelecidos nas relações sociais e de trabalho de libertos da Ilha de Santa Catarina entre os anos 1840 e 1880, o autor se deparou com um significativo número de contratos envolvendo a prestação de serviços domésticos. Atestando isso, Lima desenvolveu uma análise dos contratos de locação de serviços domésticos que foi além do enfoque nas "sobrevivências de uma ordem em deterioração" ou na confirmação de que os libertos "estavam paralisados pelos valores imóveis da escravidão". Na verdade, o autor procurou enfatizar os compromissos firmados e negociações feitas entre libertos e patrões, num confronto de expectativas distintas e de rearranjos em relações sociais de subordinação e de dependência que sofriam profundas transformações ${ }^{40}$. A permanência de ex-escravos nos serviços domésticos, por meio de contratos de locação de serviços, apareceu, então, no trabalho de Lima muito mais como uma estratégia de redução das incertezas, frente à precariedade, colocadas pela emergência do "mercado de trabalho livre", do que como uma "contiguidade entre escravidão e liberdade" ${ }^{41}$.

Com essas resumidas referências, é possível notar que assim como parece ter acontecido em relação aos estudos das relações raciais, as pesquisas históricas recentes sobre pós-emancipação, o serviço doméstico emergiu como parte importante da análise. Mais uma vez, a busca pelo destino dos escravos levou os historiadores a se depararem com o universo do trabalho doméstico. Esse apareceu como um dos principais meios de sobrevivência da população trabalhadora no dito mercado de trabalho livre e cujo passado se cruzava com a história da escravidão no Brasil. No entanto, mesmo com o risco de se considerar apenas a escravidão como geradora de permanências ou determinante primário daqueles processos históricos citados, as pesquisas históricas mencionadas, ao contrário, revelaram aspectos de dinâmicas históricas próprias da pós-emancipação e que vão muito além de uma interpretação única, pela via de heranças escravistas.

\footnotetext{
39 LIMA, Henrique Espada. Trabalho e lei para os libertos na Ilha de Santa Catarina no século XIX: arranjos e contratos entre a autonomia e a domesticidade. Cadernos AEL, Campinas, v. 14, n. 26 , p. 135-177, 2009. Vale mencionar também artigo anterior do autor que também toca no mesmo tema: Id. Sob o domínio da precariedade: escravidão e os significados da liberdade de trabalho no século XIX. Topoi, Rio de Janeiro, v. 6, n. 11, p. 289-326, jul.-dez. 2005.

40 LIMA, Henrique Espada. Sob o domínio da precariedade: escravidão e os significados da liberdade de trabalho no século XIX. Topoi, Rio de Janeiro, v. 6, n. 11, jul.-dez. 2005, p. 307309.

${ }^{41}$ Ibid., p. 307-309.
} 


\section{Aspectos da história do serviço doméstico para além da história da escravidão}

Para se pensar o tema do trabalho e dos trabalhadores domésticos em sua relação com a pós-emancipação no Brasil, talvez seja relevante discutir alguns aspectos da sua história. Desse modo, tendo em vista uma problematização das interpretações - presentes no senso comum, em narrativas e, até mesmo, em alguns estudos acadêmicos - que vinculam a história do trabalho ou do serviço doméstico à história da escravidão na formação social brasileira, propõe-se aqui ponderar, ainda que de maneira introdutória, sobre duas questões. A primeira se refere ao entendimento único de tais temas como fenômenos decorrentes da escravidão - que talvez tenha sido influenciada por parte da produção clássica dos estudos de relações raciais, como indicado anteriormente. $\mathrm{O}$ segundo ponto de reflexão busca relacionar alguns processos relativos à história do serviço doméstico com os desafios da (re) construção da sociedade brasileira após o término da escravidão, tal como nos deram pistas alguns historiadores interessados na pós-emancipação.

No que tange à primeira questão, pode-se dizer, de saída, que não é possível compreender a história do serviço/trabalho doméstico no Brasil sem considerar as suas relações com a história da escravidão moderna. Desde os primórdios da colonização portuguesa na América, a escravidão doméstica compreendeu uma das principais modalidades de exploração da força de trabalho escravizado. No decorrer de todo o período colonial, os escravos africanos - isso sem aqui se considerar a escravização de indígenas - foram figuras fundamentais nos domicílios, fossem nos campos ou nas cidades. Em uma sociedade ideologicamente avessa ao trabalho manual e economicamente muito dependente da força de trabalho humana - como era o caso da colônia portuguesa na América - grande foi o contingente de trabalhadores escravizados alocados nos domicílios para o desempenho das funções domésticas, que incluíam não só as atividades de subsistência, de cuidado ou de manutenção, mas a própria produção familiar ${ }^{42}$. A permanência do sistema escravista como forma de dominação e exploração do trabalho no contexto de independência política e de formação da Nação, no chamado período imperial, garantiu que a escravidão doméstica se mantivesse ativa, especialmente nos centros urbanos, em crescente desenvolvimento. Em algumas cidades, como na Corte Imperial - que durante boa parte do século XIX constituiu a principal cidade escravista das Américas - os escravos domésticos constituíam a força de trabalho escravo dominante, ao compor o maior contingente da população cativa urbana ${ }^{43}$.

\footnotetext{
42 ALGRANTI, Leila Mezan. Famílias e vida doméstica. In: Souza, Laura de Mello e. (Org.). História da vida privada no Brasil: cotidiano e vida privada na América Portuguesa. São Paulo: Cia das Letras, 1997, v. 1, p. 83-154, p. 43.

${ }^{43}$ SOARES, Luiz Carlos. O "povo de Cam" na capital do Brasil: a escravidão urbana no Rio de Janeiro do século XIX. Rio de Janeiro: Faperj - 7Letras, 2007, p. 107.
} 
Sendo assim, é possível afirmar que não há como recuperar aspectos da história do serviço doméstico sem se remeter à sua conexão ao passado escravista brasileiro, no qual os escravos domésticos tiveram importância crucial. Contudo, atestar esse tipo de fato não pode significar 0 estabelecimento de uma relação simplista ou puramente determinista entre a escravidão e o trabalho doméstico na história do Brasil, tal como se dá de certa forma no entendimento em torno da noção de herança. Normalmente, as interpretações contemporâneas que, dessa forma, associam de maneira direta os problemas do trabalho doméstico remunerado, seja no século XX ou no início do XXI, à escravidão tendem a compreendê-la como algo cristalizado e homogêneo. Ou seja, o sistema escravista é visto como um fenômeno histórico que se deu de forma monolítica e sem mudanças do início da colonização portuguesa até o seu término oficial em 1888. Nesse caso, uma das imagens recorrentemente acionadas para se tratar das origens históricas do trabalho doméstico remunerado - seja em qualquer contexto histórico - é dos escravos domésticos conforme foram abordados na obra de Gilberto Freyre ${ }^{44}$. O tempo longínquo e idealizado de uma escravidão que condenou o presente é, com frequência, retomado como um elemento retórico obrigatório nas análises do trabalho doméstico remunerado contemporâneo, em que referências a sinhás e a escravas são lugar-comum para a associação com patroas e empregadas da atualidade.

Entretanto, se essa é uma visão ainda muito presente no entendimento comum acerca da história do serviço doméstico no Brasil - e, portanto, nas análises e narrativas que são feitas sobre o assunto -, talvez isso se relacione com duas outras problemáticas, também muito presentes no modo de ver 0 tema e que se encontram na base dos entendimentos sobre o trabalho doméstico na história. A primeira é a compreensão de que o trabalho doméstico, no passado brasileiro, foi sempre e exclusivamente realizado por trabalhadores africanos ou afrodescendentes escravizados. E a segunda é a ideia de certa incompatibilidade entre a escravidão e o capitalismo ou entre este e o trabalho doméstico remunerado.

No primeiro caso, é importante considerar que se a escravidão doméstica foi uma das modalidades típicas de exploração da força de trabalho escravizada isso não significa que os escravos fossem os únicos trabalhadores atuantes nos chamados serviços domésticos na história brasileira. No decorrer dos séculos de vigência da escravidão, trabalhadores livres executaram também atividades domésticas no mundo do trabalho. Na verdade, a prestação de serviços domésticos, de longa data foi uma das principais ocupações de mulheres pobres, fossem libertas ou livres. Por vários fatores, como a ausência de qualificações para a execução de outras atividades profissionais ou por ser ocupação considerada típica da condição feminina ou de aprendizado infantil, o trabalho doméstico remunerado foi recurso com frequência acionado pela população trabalhadora como forma de sobrevivência material ${ }^{45}$. Isso tanto

44 FREYRE, Gilberto. Casa-grande \& senzala; Id. Sobrados e mucambos decadência do patriarcado e desenvolvimento do urbano. 15a ed. São Paulo: Global, 2004.

${ }^{45}$ SOUZA, Flavia Fernandes de. Escravas do lar: as mulheres negras e o trabalho doméstico na Corte Imperial. In: XAVIER, Giovana; FARIAS, Juliana Barreto; GOMES, Flávio dos Santos (org.). 
entre a parcela da população livre branca, quanto naquela denominada "de cor" (preta ou parda) ${ }^{46}$. Além disso, em contextos como o da segunda metade do século XIX, com o desenrolar de processos históricos como o do fim do tráfico de africanos e da imigração de trabalhadores europeus para o Brasil, houve em algumas cidades uma diminuição do número de escravos domésticos urbanos e o aumento do número de criados e criadas livres ${ }^{47}$. Até porque a prestação de serviços domésticos foi uma das principais formas de ingresso de trabalhadores estrangeiros no mundo do trabalho urbano ${ }^{48}$. Em alguns casos, havia, inclusive, preferências por parte de empregadores por criadas e criados livres e brancos, em especial estrangeiros, tal como revelam anúncios de ofertas de emprego publicados em jornais diários do final do século XIX e do início do século XX. De qualquer forma, em certos espaços urbanos, como o da cidade do Rio de Janeiro - onde o trabalho doméstico (escravizado ou livre) tendeu a se expandir consideravelmente, se comparado ao campo -, a convivência entre trabalhadores livres, libertos e escravizados era extremamente comum, não só no setor do serviço doméstico, mas em outros espaços de trabalho ${ }^{49}$.

Esse é um ponto de discussão relevante porque o entendimento de que os trabalhadores domésticos, durante a existência da escravidão, eram unicamente escravos pode levar - e normalmente leva - a uma justificativa comum para a preponderância numérica de afrodescendentes nas atividades domésticas no século XX e neste início do século XXI. Ou seja, pensando-se dessa forma, pode-se chegar à conclusão de que se as trabalhadoras domésticas contemporâneas são majoritariamente negras, isso se deve ao fato de que no passado o trabalho doméstico era feito por escravos africanos e seus descendentes. Esta que, dependendo do ponto de vista, pode ser uma interpretação válida, até certo ponto, se vista como explicação absoluta acaba por negar aspectos da história da própria escravidão e de processos históricos desenvolvidos no contexto da pós-emancipação. Nesse caso, é preciso lembrar que, no Brasil - assim como em outras sociedades escravistas -, a passagem do trabalhador escravizado para o trabalhador livre envolveu formas de inserção

Mulheres negras no Brasil escravista e do pós-emancipação. São Paulo: Selo Negro, 2012, p. 244-260.

${ }^{46}$ Mesmo com a ausência de dados censitários sobre a questão da cor dos trabalhadores domésticos, historiadores que se dedicaram ao estudo do trabalho doméstico demonstraram evidências da variedade na composição étnica/racial do contingente de criadas e criados domésticos da segunda metade do século XIX e das primeiras décadas do século XX, em várias cidades do Brasil. Cf. SILVA, Maciel Henrique Carneiro da. Domésticas criadas entre textos e práticas sociais: Recife e Salvador (1870-1910). Tese (Doutorado em História) - Faculdade de Filosofia e Ciências Humanas, Universidade Federal da Bahia, Salvador, 2011, p. 104-115; GRAHAM, Sandra Lauderdale. Proteção e obediência: criadas e seus patrões no Rio de Janeiro, 1860-1910. Rio de Janeiro: Cia das Letras, 1992.

47 SOARES, Luiz Carlos. O "povo de Cam" na capital do Brasil: a escravidão urbana no Rio de Janeiro do século XIX. Rio de Janeiro: Faperj - 7 Letras, 2007, p. 76-77; 81.

${ }^{48}$ MATOS, Maria Izilda Santos de. Cotidiano e cultura: história, cidade e trabalho. São Paulo: Edusc, 2002, p. 119; 122-125.

${ }^{49}$ MATTOS, Marcelo Badaró. Escravizados e livres: experiências comuns na formação da classe trabalhadora carioca. Rio de Janeiro: Bom Texto, 2008; GRAHAM, Sandra Lauderdale. Op. cit. 
social, em especial no mercado de trabalho, que se deram em meio a um cenário de desigualdades - fossem elas estabelecidas por limitações no acesso à cidadania para a população egressa ou descendente do cativeiro, fossem pela (re)construção de mecanismos de distinções sociais eivados de marcadores raciais, por sua vez caracterizadores de lugares sociais subalternos.

No que se refere ao segundo ponto mencionado, a respeito da ideia de incompatibilidades radicais entre escravidão, capitalismo e trabalho doméstico remunerado, trata-se de outro ponto importante para se considerar na análise do tema em discussão, sob um ponto de vista histórico mais amplo. Em primeiro lugar, embora essa seja uma questão complexa, que aqui dificilmente poderia ser objeto de uma atenção mais detida, é fundamental destacar que se a história do trabalho doméstico em grande parte se confunde com passado escravista brasileiro, isso não significa que a escravidão deva ser entendida como uma instituição ou sistema que se manteve inalterado do início ao fim. Além das inúmeras conjunturas, enfrentadas em épocas coloniais e imperiais, que afetaram a permanência estrutural do regime escravista na formação social brasileira, como vêm demonstrando alguns historiadores, a escravidão nas Américas foi reelaborada com a ascensão e o desenvolvimento do modo de produção capitalista no século XIX ${ }^{50}$. E por mais que, à primeira vista, não pareça ser essa é uma discussão importante no que diz respeito à história do trabalho doméstico, tal debate se liga a vários outros problemas históricos, presentes no plano de fundo da discussão em questão. Um exemplo disso é a problemática das relações entre trabalho escravo e trabalho livre assalariado no desenvolvimento histórico da economia mundial capitalista, uma vez que essas relações não podem ser vistas como parte de um processo evolutivo linear, dada até mesmo a existência de várias e combinadas formas de exploração do trabalho, fosse ele escravo, livre, autônomo, assalariado, contratado, alugado, urbano, rural ou doméstico ${ }^{51}$.

Em segundo lugar, cabe questionar a ideia comumente aceita de que 0 trabalho doméstico é uma espécie de "anomalia" no cenário econômico e social atual ou resquício de algo passado que caminha para um inexorável e próximo fim. Trata-se de outra questão complexa, principalmente se for considerado o elevado contingente de trabalhadores domésticos ativos no Brasil, o qual ocupa o primeiro lugar no ranking atual dos dez países com o maior número de trabalhadores domésticos. Vale destacar que nesta condição se encontram tanto aqueles países denominados de "emergentes" (como Índia, Indonésia,

\footnotetext{
${ }^{50} \mathrm{O}$ historiador Dale Tomich, na esteira de outros estudos anteriores, denominou esse processo de "segunda escravidão", em um esforço de compreensão da diferença entre os sistemas escravistas existentes em regiões do Sul dos Estados Unidos, de Cuba e do Brasil no século XIX - segundo o autor, criados como parte dos processos de reestruturação da economia mundial em relação aos regimes escravistas que precederam a emergência do capital industrial e do trabalhado assalariado. Cf. TOMICH, Dale W. Pelo prisma da escravidão: trabalho, capital e economia mundial. São Paulo: Edusp, 2011, cap. 3; ver também o clássico: WILLIAMS, Eric. Capitalismo e escravidão. Trad. de Denise Bottmann. São Paulo: Cia das Letras, 2012.

${ }^{51}$ Para uma discussão contemporânea acerca das diferentes formas de exploração do trabalho ao longo da história ver: LINDEN, Marcel van der. Trabalhadores do mundo: ensaios para uma história global do trabalho. Trad. Patrícia de Queiroz Carvalho Zimbres. Campinas, SP: Unicamp, 2013, parte 1 .
} 
Filipinas, México, Colômbia, Argentina, Arábia Saudita), quanto alguns dos considerados mais desenvolvidos (como Estados Unidos e Espanha) ${ }^{52}$. Aliás, ao que parece, na contramão de matérias e pesquisas que preveem o fim do emprego doméstico ${ }^{53}$, encontra-se uma série de discussões que chamam a atenção para o aumento do número de domésticos em vários lugares do mundo ${ }^{54}$. Isso incluindo os debates levados a cabo na 99a e $100^{a}$ Conferências Internacionais do Trabalho (CIT) organizados pela Organização Internacional do Trabalho (OIT), em 2010 e 2011, para a criação de uma convenção visando a trabalho digno e decente para os mais de cinquenta milhões de trabalhadores domésticos no mundo ${ }^{55}$.

Do ponto de vista histórico, um maior entendimento da relação entre o capitalismo e o emprego doméstico é fundamental. Por um lado, porque esse é um tema que se já foi alvo de intensos debates, tal como o que caracterizou algumas discussões conceituais dos anos 1970, sobretudo em meios marxistas (acerca da opressão das mulheres no capitalismo e da situação do trabalho doméstico executado pelas donas de casa) ${ }^{56}$, ainda são iniciais os estudos históricos sobre o assunto, em especial no campo da História Social. Por outro lado, porque, considerando o que indicam alguns estudos históricos recentes, é preciso entender os motivos que levaram o serviço doméstico e seus trabalhadores a se tornaram um "problema social" exatamente no contexto de emergência da chamada modernidade capitalista ${ }^{57}$. No decurso do século XIX e do início do século $X X$, o serviço doméstico ganhou dimensão pública, sendo visto como em estado de crise e caracterizando-se como tema de interesse na imprensa e na pauta de discussões de intelectuais e autoridades públicas em diferentes lugares do mundo. Apenas para citar alguns exemplos de que se têm

${ }^{52}$ BRASIL é o país com maior número de empregados domésticos no mundo. Isto é. 9 jan. 2013. Disponível em: <http://www.istoe.com.br/reportagens/266400_BRASIL+E+O+PAIS+COM+MAIOR+NUMERO+ DE+EMPREGADOS+DOMESTICOS+NO+MUNDO > . Acessado em: 5/1/2015.

${ }^{53}$ IPEA. Situação atual das trabalhadoras domésticas no país... Op. cit., p. 7; CALFAT, Marcelo. O IPEA prevê o fim do emprego doméstico em poucos anos. Correio de Uberlândia. Uberlândia, 29 maio 2011. Disponível em: <http://www.correiodeuberlandia.com.br/cidade-e-regiao/ipeapreve-fim-do-emprego-domestico-em-poucos-anos/>. Acessado em: 5/1/2015.

54 A NOVA "era dos criados" nos EUA. Pragmatismo político. 28 jul. 2014. Disponível em: <http://www.pragmatismopolitico.com.br/2014/07/nova-era-de-criados-nos-eua.html>.

Acessado em: 5/1/2015.

${ }^{55}$ OIT. Entra em vigor a Convenção sobre Trabalho Doméstico da OIT. Publicado no site: OIT Organização Internacional do Trabalho - Escritório no Brasil (http://www.oitbrasil.org.br).

${ }^{56}$ HIMMELWEIT, Susan. Trabalho doméstico (verbete). In: BOTTOMORE, Tom (ed.). Dicionário do pensamento marxista. $2^{a}$ ed. Rio de Janeiro: Zahar, 2012, p. 566-569. No Brasil, essa discussão foi retomada pela socióloga Heleieth Saffioti em finais da década de 1970. Cf. SAFFIOTI, Heleieth. Emprego doméstico e capitalismo. Petrópolis: Vozes, 1978.

57 Sobre usos e críticas acerca do conceito de "modernidade" ou "modernidade capitalista" algumas referências importantes são: ANDERSON, Perry. Modernidade e revolução. Novos Estudos Cebrap, São Paulo, n. 14, p. 1-15, fev. 1986; BERMAN, Marshall. Tudo o que é sólido desmancha no ar. a aventura da modernidade. São Paulo: Companhia das Letras, 1986; KUMAR, Krishan. Modernidade (verbete). In: OUTHWAITE, William; BOTTOMORE, Tom (Org.). Dicionário do pensamento social do século XX. Rio de Janeiro: Zahar, 1996. 
algumas referências pode-se apontar para situações como a dos EUA, do Canadá e da Suíça no entresséculos XIX-XX, onde o serviço doméstico era discutido como um problema ${ }^{58}$; ou para os casos de aprovação de legislações específicas para os criados domésticos, ao longo do século XIX, em regiões da Índia colonial ${ }^{59}$, de Portugal ${ }^{60}$, da Espanha ${ }^{61}$, da Argentina ${ }^{62}$, de Porto Rico ${ }^{63}$, entre outros. Além dos fenômenos ocorridos na Inglaterra - berço da industrialização - ainda no século XVIII, quando "the servant question" já se colocava, se complicando no século XIX com o processo de feminização do setor e de enorme crescimento do contingente de trabalhadores devido a ondas migratórias para centros urbanos como Londres ${ }^{64}$.

Embora essa seja uma questão que ainda precisa ser desenvolvida com pesquisas históricas, pode ser esta uma chave importante de compreensão das problemáticas do serviço doméstico no mundo contemporâneo, que, ao que tudo indica, se já eram existentes em tempos mais remotos da história, em meio a regimes de servidão e de escravidã ${ }^{65}$, tornaram-se mais complexas com a emergência do capitalismo. Afinal, independentemente dos consensos ou dissensos em relação ao papel executado pelo emprego doméstico no capitalismo, não se pode negar a sua importância no quadro geral atual de funcionamento do sistema. De qualquer maneira, esse é um elemento que pode contribuir para se discutir a ideia comum de "não lugar" do trabalho doméstico no contexto econômico e social ou de fim próximo desse tipo de emprego. Afinal, recuperando aqui reflexões feitas pela historiadora inglesa Bridget Hill, ao comparar as diferentes situações históricas de trabalhadores domésticos na

58 David M. Katzman. Seven days a week: women and domestic service in industrializing America. New York: Oxford University Press, 1978, p. 223; CHARRON, Catherine. La question du travail domestique au début du xxe siècle au Québec: un en jeu à la Fédération Nationale Saint-Jean-Baptiste, 1900-1927. Dissertação (Mestrado em História) - Faculté des Études Supérieures, I'Université Laval, Laval, 2007; Head-König, Anne-Lise Head-König. La pénurie de domestiques en Suisse et ses remèdes (1870-1939). Sextant. Revue bisannuelle publiée par le Groupe interdisciplinaire d'Etudes sur les Femmes avec le concours du Fonds Suzanne Tassier (ULB), Bruxelles, n. 15/16, p. 127-148, 2001.

59 MOHAPATRA, Prabhu. Informalidade regulamentada: construções legais das relações de trabalho na Índia Colonial (1814-1926). Cadernos AEL, Campinas, v. 14, n. 26, p. 53-88, 2009, p. 68-69.

${ }^{60} \mathrm{PAZ}$, Olegário. Empregadas domésticas, mulheres em luta: o serviço doméstico em Portugal das origens ao fascismo. Lisboa, Porto, Coimbra: Base, 1987, p. 61-68.

${ }^{61}$ SARASÚA, Carmen. Criados, nodrizas y amos: el servicio doméstico en la formación del mercado de trabajo madrileño, 1758-1868. Madrid: Siglo XXI, 1994.

62 REMEDI, Fernando J. "Esta descompostura general de la servidumbre": las trabajadoras del servicio doméstico en la modernización argentina (Córdoba, 1869-1906). Secuencia, n. 84, p. 43-69, sep.-dic. 2012.

63 RODRIGUEZ, Félix V. Matos. ¿Quién trabajará? Trabajo doméstico, esclavitud urbana y abolición em San Juan em el siglo XIX. Revista de Ciencias Sociales, Rio Piedras, n. 4, p. 219245, jan. 1998.

${ }^{64}$ HOBSBAWM, Eric. A era do capital (1848-1875). Trad. de Luciano Costa Neto. $2^{\mathrm{a}}$ ed. Rio de Janeiro: Paz e Terra, 1979, p. 219; 228; BRIDGET, Hill. Servants. English domestics in the Eighteenth Century. Oxford, UK: Clarendon Press; New York: Oxford University Press, 1996.

${ }_{65}$ Sobre algumas questões acerca das relações entre escravidão e servidão em tempos mais remotos ver: HEERS, Jacques. Escravos e domésticos na Idade Média no mundo mediterrâneo. São Paulo: Difel, 1983. 
Inglaterra setecentista com a dos países até há pouco tempo chamados de "terceiro mundo", concluiu que o trabalho doméstico remunerado deve ser pensado não só como um lugar ocupado por trabalhadores em situação de severas "vulnerabilidades"66 sociais, mas, também, como um "componente importante na reprodução da posição de classe e das vantagens de grupos privilegiados em países subdesenvolvidos ${ }^{\prime \prime 67}$.

Voltando para o caso brasileiro, se essa pode ser uma discussão válida de ser investigada, não se deve perder de vista que no Brasil o cenário internacional de "crise" no serviço doméstico, típico da virada do século XIX para o século XX, assim como em outras sociedades, se deu de forma estreitamente relacionada ao processo de emancipação dos escravos. E isso vem ao encontro do último ponto de discussão deste texto e com o qual ele foi iniciado: a regulamentação do serviço doméstico, que emergiu no cenário da emergência da modernidade brasileira. Em todas as discussões sobre o serviço doméstico em diferentes cidades do Brasil no final do século XIX e início do $X X^{68}$ o grande problema de fundo era o que fazer com esse setor de serviço após o fim da escravidão, quando este seria composto apenas por trabalhadores livres. Ou seja, este era um dos desafios de uma sociedade recém-saída da escravidão e que, certamente, não afetava apenas os exescravos, mas todos os trabalhadores, fossem eles egressos ou não do cativeiro.

Como já se sabe, a regulamentação do trabalho foi um problema que se colocou, em várias formações sociais, na medida em que se constituía o mercado de trabalho livre, uma vez que visava, entre outras coisas, à garantia da manutenção dos contratos de trabalhos - com a criminalização dos trabalhadores que não cumprissem as normas estabelecidas -, a

66 Segundo Hill, uma característica comum às empregadas domésticas era a sua vulnerabilidade, seja por sua origem - já que muitas são provenientes de fluxos migratórios rural-urbanos -, seja pelos altos índices de desemprego ou pela facilidade com que podem ser exploradas, maltratadas e abusadas - física ou moralmente. Cf. HILL, Bridget Irene. Algumas considerações sobre as empregadas domésticas na Inglaterra do século XVIII e do Terceiro Mundo de hoje. Varia História, Belo Horizonte, n. 14, p. 22-33, set. 1995, p. 29-33.

${ }^{67}$ Ibid., p. 33.

68 Nos últimos anos, algumas pesquisas históricas revelaram processos relativos à regulamentação do serviço doméstico no final do século XIX e início do século XX nas cidades do Rio de Janeiro, de São Paulo, do Recife, de Salvador e do Rio Grande. SOUZA, Flavia Fernandes de. Para casa de família e mais serviços: o trabalho doméstico na cidade do Rio de Janeiro no final do século XIX. Dissertação (Mestrado em História) - Faculdade de Formação de Professores, Universidade do Estado do Rio de Janeiro. São Gonçalo, 2010, cap. 3; MATOS, Maria Izilda Santos de. Cotidiano e cultura; SILVA, Maciel Henrique Carneiro da. Domésticas criadas entre textos e práticas sociais; TELLES, Lorena Féres da Silva. Libertas entre sobrados. contratos de trabalho doméstico em São Paulo na derrocada da escravidão. Dissertação (Mestrado em História) - Faculdade de Filosofia, Letras e Ciências Humanas, Universidade de São Paulo, São Paulo, 2011; COSTA, Ana Paula do Amaral. Criados de servir estratégias de sobrevivência na cidade do Rio Grande (1880-1894). Dissertação (Mestrado em História) Instituto de Ciências Humanas, Universidade Federal de Pelotas, Pelotas, 2013. 
disciplinarização e a restrição da mobilidade espacial da força de trabalho ${ }^{69}$. No caso de uma sociedade pós-escravista isso ganhou contornos mais complexos, pois todo o processo de regulamentação do trabalho terminava por envolver as tensões e conflitos em torno de sentidos diversos de autonomia, para patrões e empregados. Sendo assim, a questão da regulamentação do trabalho doméstico - que atualmente ainda é ponto de debate, mesmo que em perspectivas completamente diferentes - surgiu originalmente, no Brasil, não só como elemento inerente à modernidade capitalista, mas especialmente como uma tentativa de solução para um dos desafios colocados pela emancipação dos escravos. Se a prestação de serviços domésticos se tornou, ao longo do século XX, um espaço de expressão de desigualdades socioraciais ou de subalternidade, isso foi resultado não só de "sobrevivências do passado escravista", mas de processos históricos ocorridos, muitas vezes em contextos diferentes, mas em um grande cenário de pós-emancipação. E neste estiveram presentes não apenas continuidades de práticas e de valores escravistas, mas, também, novas dinâmicas sociais, que envolveram a organização do mundo do trabalho, a existência de clivagens raciais e inúmeras lutas pela expansão de direitos de cidadania.

\section{Sobre a autora}

Flavia Fernandes de Souza é doutoranda no Programa de Pós-graduação em História da Universidade Federal Fluminense (PPGH-UFF) e Bolsista Nota 10 da Fundação Carlos Chagas Filho de Amparo à Pesquisa do Estado do Rio de Janeiro (Faperj). E-mail: flaviasza@yahoo.com.br.

Artigo recebido em 29 de janeiro de 2016.

Aprovado em 23 de agosto de 2016.

${ }^{69}$ MOHAPATRA, Prabhu. Informalidade regulamentada: construções legais das relações de trabalho na Índia Colonial (1814-1926). Cadernos AEL, Campinas, v. 14, n. 26, p. 53-88, 2009; GEBARA, Ademir. O mercado de trabalho livre no Brasil (1871-1888). São Paulo: Brasiliense, 1986. 